\title{
Contemporary Tibetans' Cultural Cognition, Shifts and Influencing Factors: A Case Study of Shigatse in China
}

\author{
Yan Sun $^{1 *}$, Hao Zhang ${ }^{1,}$ Weiwei Wang ${ }^{2}$

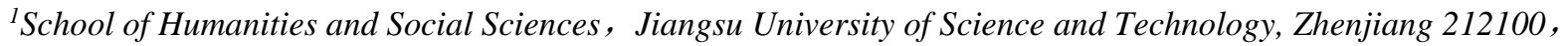 \\ Jiangsu, China; \\ ${ }^{2}$ School of Economics and Management, Jiangsu University of Science and Technology, Zhenjiang 212100, \\ Jiangsu, China \\ *Corresponding author. Email: saadiya99@126.com
}

\begin{abstract}
Traditional and modern culture together constitute Tibetan local cultures in contemporary society. The objective of this research is to explore Tibetans' cultural cognition, recent shifts and the factors influencing it. By applying various qualitative and quantitative methods of analysis, this study finds that Tibetans' cultural integration is typically expressed in tradition preservation, through the dimensions of daily life and social interactions, while their cultural separation is demonstrated through religious beliefs, along with other cognition types that tend towards modern cultures incorporating festivals. Their cognition is associated with economic activities, job needs, occupation choices and personal development. In practice, Tibetans' cultural cognition is strongly influenced by individuals' psychological responses and social development. Pressure from foreign cultures and globalization, coupled with further education, and a higher degree of ethnic belonging together enhance Tibetans' adherence to their traditional culture. Meanwhile, changes in social relations, positive impacts of foreign culture, improvements in educational facilities, modern science and technology, and national policies can lead to modern cultural cognition. These results can help contextual understanding of contemporary culture in Tibet and are key for governments and stakeholders to effectively protect Tibetan traditional culture and promote its sustainable development.
\end{abstract}

Keywords: Cultural cognition; Tradition; Modernization; Shigatse

\section{INTRODUCTION}

In the context of cultural shifts, peoples with different cultural characteristics have different cognition and viewpoints which force people from different cultural backgrounds to consider how to best participate in local cultural environments [1]. Local cultural cognition is the representation of a conceptual relationship based on the existence of cultural variations and diversities. This includes: languages, life customs, religious beliefs, psychological emotions, heroes, values, rituals, behaviors, traditions, norms, attitudes, social relationships, arts, purposes, work habits, self-policing strategies, leisure patterns, techniques, and institutions [2]. On the other hand, local cultural cognition also involves two or more independent cultures [3]. This directly leads to cultural transformation seeking consistency between self and other cultures in psychological and behavioral dimensions, and is also a response to local cultural cognition shifts [4]. Many phenomena are observed when two different cultures interchange, and are closely related to cultural adaptation, imitation, rejection and deculturation [5]. Shifts in cultural cognition are dependent on a specific environment [6]. Intercultural inclination combines both cultures through selfrealization [3], as local people adapt to new cultures. Individual psychological responses link to the changes in attitudes and behaviors. The key mediators of cultural cognitive shifts are the psychological responses, which are associated with the variations in values caused by intercultural communication, and underline the processes driving stress-adaptation-growth [7].

Contemporary Tibetan local cultures consist of traditional and modern. Tibet is the world's highest 
region. The unique social environment and the harsh natural environment helped forge a Tibetan culture with the attributes of plateau, tradition, religion and closure. Since the liberation of Tibet in 1959, the PRC and the Communist Party of China (CPC) have implemented a series of major construction projects, aided by developed Chinese provinces or municipalities, with corresponding supportive policies. These have boosted Tibet's economic development, social stability, opening-up and modernization. Tibetans have frequently contacted, interacted and exchanged with foreign cultures and immigration, which has forced Tibetans to re-evaluate their traditional cultures and has endowed cultural cognition with new meanings. This has enabled cultural dialogue with each other by in-depth exchange and communication. Tibetan People acquired new cultural characteristics and reconstructed the self-concept. Some Tibetans tend to recognize and accept modern culture in high local cultural cognitive environments, while others may not effectively interact with other cultures and only adapt to local traditional cultures. As a result, there is a series of cultural cognitive shifts in the process of Tibetan traditional and modern cultural communication. Some Tibetans have high Tibetan traditional cultural awareness, while other Tibetans have high modern cultural cognition. Some researchers have proposed the theory of Chinese multi-integration: this means that high-level cognition does not necessarily replace or exclude low-level cognition, and different cultural cognition levels can coexist [8]. Therefore, the above cultural cognitive classifications provide a paradigm and research framework for studying cultural cognitions among different cultures in ethnic minority-dominated regions. There are two possibilities for Tibetan cultural shifts: first, Tibetans' consciousness is gradually perfected or selfreconstructed before they transform into the modern culture; second, social transformation and cultural conflicts jointly result in a tendency towards Tibetan traditional culture [9]. Although the distance between traditional and modern cultures becomes narrower, according to existing research, some negative alien cultural effects also deepen the cognition of traditional culture among Tibetans. Some studies find that Tibetan cultural production originates from an imaginary locality, which means that some Tibetans' cultural cognition tends to reflect traditional culture. Furthermore, some Tibetans believe that traditional cultures should be fully or partially protected. Meanwhile, some researchers have proposed a Tibetan cultural circle structure between modern and traditional cultures. Some studies hold that Tibetan Buddhism is the spiritual pillar of Tibetans, and that it shapes the deep-rooted religious-cultural perception of the Tibetan people [10]. Whether or not the Tibetans adapt to cultural transformation, these are the key factors to achieve the expected goal of economic and social development in Tibet. Overall, cultural cognitive process may be considered as a continuous varied process. Contextual variables could impact cultural cognitive shifts [11].
In recent years, research on Tibetan cultural changes and people's cultural cognition has mainly focused on languages, interpersonal communications, value systems, cultural products, education, and traditional cultural symbols. While some previous studies have considered Tibetan traditional cultural protection, values, adaptability, ethnic cognition and sustainable development [12], the deep cultural cognitions in Tibetan people's inner psychological needs, the actual productivity, and living requirements have not been discussed. Therefore, it is necessary to clarify Tibetans' basic cognition boundaries between traditional and modern cultures [13]. Specifically, it is urgent to elaborate on the Tibetans' local cultural cognition and its influencing factors. Some studies have tried to systematically identify which factors influence cultural cognition and shifts. More importantly, researchers usually adopt a dynamic perspective and adaptive adjustment to study local cultures. Therefore, in this study we use in-depth interviews, questionnaires, factor analysis, weighting of coefficients of variation, and multiple regression models to explore the subjects from humanistic perspectives, local meanings and policy vectors. The rest of this study is organized as follows. Section 2 presents the materials and methods; Section 3 describes the results, which are discussed in Section 4; and Section 5 presents the conclusions.

\section{MATERIALS AND METHOD}

\subsection{Case study}

Sangzhuzi District, Shigatse City is a typical case with which to study contemporary Tibetan local cultural cognition, and shifts among Tibetan people and their influencing factors. Firstly, Shigatse is the place where the Panchen is located. Tibetan Buddhism is the tradition associated with a great number of historical and cultural heritages, including the Tashihunpo Monastery, Zongshan, Panchen's Palace and other religious buildings in the urban area. Secondly, since 1959, the PRC has made extensive financial investments, while support from Shanghai, Shandong, Heilongjiang, Jilin in China as well as the state-owned enterprises of Baosteel Group and Sinochem Group has played an important role in Shigatse's modernization. Thirdly, Shigatse City's culture is deeply affected by modernization, globalization and digitalization. These characteristics have caused Shigatse to become the center of cultural integration and conflict.

\subsection{Survey design, indicators and data collection}

The study of Tibetan people's local cultural cognition and change is based on five perspectives: daily life, tradition preservation, modern festivals, social interactions and religious beliefs. There are 17 variables to measure the cultural cognition [14]. The five-point 
Likert scale is applied to define people's cognitive level: "Strong Cognition=5, Cognition=4, Neutrality=3, UnCognition=2 and Strong un-Cognition=1". "Strong Cognition $=5$ " means that the Tibetans fully adhere to the Tibetan traditional culture, and "Strong un-Cognition=1" indicates that the Tibetans turn completely to modern culture. The remaining three options show different degrees of intermediate or mixed states. Daily life mainly includes Tibetan people's traditional cultural inheritance, modern cultural recognition and religious practice in Tibetans' ordinary life. Variables in daily life are the level of Tibetan food preference and its inheritance (LTF), the level of Tibetan clothing preference and its inheritance (LTC), the degree of difference, preferences and trust between Tibetan and non-Tibetan friends (TNF), the degree of piety or practice of mountain worship every day (PMW), the frequency or degree of using Chinese at work (FCW), as well as the frequency of using Tibetan language in daily life and social interactions (FTL). The aspect of tradition preservation represents Tibetans' adherence to Tibetan traditional customs. This is associated with the level of compliance with Tibetan traditional customs (TTC), the level of compliance with Tibetan traditional marriage etiquettes (TME), the level of compliance with Tibetan traditional funerals (TTF) and the level of compliance with traditional Tibetan festivals (CTF). The dimension of modern festivals reflects the degree to which Tibetans are influenced by non-Tibetan Chinese culture, Western culture and South Asian culture. This includes the level of familiarity with modern festivals (FMF) and the degree of recognition for, and compliance with, national statutory holidays (NSH) [15]. The dimension of social interactions signifies the relationship between Tibetans and non-Tibetans; the relevant variables are the cognitive degree of living with non-Tibetan residents (NTR), the cognitive degree of deep interaction with non-Tibetan residents (INT) and the cognitive degree of intermarriage between Tibetans and non-Tibetans (IMN). The aspect of religious beliefs denotes the people's loyalty and familiarity with Tibetan Buddhism. It is often expressed in terms of the degree of familiarity with Tibetan Buddhism and Bon Buddhism (FTB) and the degree of familiarity with the history of temple development (FHT) [16].

There are six dimensions (demographic characteristics, alien cultural impacts, traditional cultural restrictions, policies, modern development and social conditional changes) which measure the influencing factors of Tibetans' cultural cognition and shifts [17,18]. Meanwhile, the influencing factors include 18 items to explore the mechanisms of the Tibetans' cultural cognition and shifts. Similarly, influencing factors' indicators are also assigned according to the five-point Likert scale of "Yes=5, Relative Yes=4, Neutrality=3, Relative $\mathrm{No}=2, \mathrm{No}=1 "$ ". "Yes=5" signifies factors that strongly influence the Tibetans' cultural cognitive characteristics. "No=1" signifies the relevant variables that do not completely influence the Tibetan people's cultural cognitive features. The other choices are intermediate levels of cognition. Variables corresponding to the dimension of demographic characteristics are gender, age, occupation (OP), the level of education (EL) and residential time (RT). The term of alien cultural impacts represents the influence of alien culture (IA), the relative openness of alien culture (AO), the level of familiarity of alien culture (FA), and the degree of interest in alien culture (IC). The aspect of traditional cultural restrictions means the degree of ethnic belonging (EB) and the degree of Tibetan cultural restriction on behavior (BR) [19]. The aspect of policy comprises the level of national policies' impact (NP), the level of counterpart assistant influence (AC) and the extent of local governments' role (LG). The dimension of modern development associates with the degree of economic development (ED), the level of using internet (UI), the level of technical application (TA), the degree of educational facilities' improvement (IE) and the degree of globalization (GL) [20]. The aspect of social conditional changes denotes the level of social openness and communication (OC), the level of social stability and development (SS), the level of Tibetan and non-Tibetan mixed residence (MR) and the level of internal responses about people's own comprehensive development (PD) [21].

The method of simple random sampling was used in the data collection process, to achieve isomorphism between the sample and the population. From May to July 2017, we conducted surveys, interviews and acquired statistical materials. Tibetans exhibit spatial agglomeration in Shigatse City. To reduce the sampling error, we also considered population distribution, migration, gender, age, occupation etc. Furthermore, Tibetans attach great importance to kinship. A large family is often divided into several households; parents in a family are highly authoritative, and can fundamentally affect the cultural values of the whole family. To avoid sampling reproducibility and to ensure each sample was independent of other selections, only one household was selected from multiple related households. The sample ratio was 1:87. In total, 59 valid questionnaires were collected, and a scientifically small sampling data can also explain the research subjects. Hence, the survey sample is representative and can be used to further study the corresponding subjects.

\subsection{Data analysis}

Factor analysis by the maximizing variance rotation method was employed to reduce data dimensionality. This was carried out in PASW Statistics 18. The coefficient of variation method was used to determine the weight of the assessment index, which overcomes disadvantages of when using an average weight. The methods of weighting coefficients of variation, cultural 
cognitive scores and stepwise line regression were objective and valid for estimating the Tibetans' cultural cognition, shifts and their influencing factors.

\subsubsection{Weighting of coefficients in the variation model}

The coefficient of variation method is used to determine the weight of the assessment's index [22]. Here we establish the original data matrix, standardize the data, compute the average and standard deviation, construct a standardized data matrix and calculate the coefficient of variation. The related formulas are as follows:

$$
\begin{gathered}
\sigma_{j}=\sqrt{\frac{1}{n} \sum_{i=1}^{n}\left(x_{i j}-\overline{x_{j}}\right)^{2}} \\
x_{i j}^{*}=\frac{x_{i j}-\overline{x_{j}}}{\sigma_{j}},(i=1,2, \cdots, n ; j=1,2, \cdots, m) \\
W_{f k}=\frac{\lambda_{k}}{\sum_{k=1}^{p} \lambda_{k}} \\
\omega_{j}=\sigma_{j} / \overline{x_{j}} \\
w_{j}=\omega_{j} / \sum_{j=1}^{m} \omega_{j}
\end{gathered}
$$

Where $x_{i j}, \bar{x}_{j}, \sigma_{j}, x_{i j}^{*}, \lambda_{k}, W_{f k}, \omega_{j}$ and $W_{j}$ are the original data, mean, standard derivation, standardized data matrix, eigenvalues, the $k^{\text {th }}$ principal factor's weight, the $j^{\text {th }}$ item's coefficient of variation, and the $j^{\text {th }}$ variables' weights.

\subsubsection{Model of cultural cognition score}

To quantify the contribution of each cultural cognitive dimension, the weights of variables corresponding to each main factor were redefined by multiplying formulas (3) and (4). The sum of weights of all principal factors is equal to the sum of weights of all variables, and the total value is 1 . The formulae are as follows:

$$
\begin{gathered}
w_{\lambda k j}=\mathrm{W}_{f k} \mathrm{w}_{j}=\frac{\lambda_{k}}{\sum_{j=1}^{p} \lambda_{k}}\left(\omega_{j} / \sum_{j=1}^{m} \omega_{j}\right) \\
\sum_{k=1}^{p} W_{f k}=\sum_{k=1}^{p} \mathrm{w}_{\lambda k j}=\sum_{k=1}^{p} \frac{\lambda_{k}}{\sum_{k=1}^{p} \lambda_{k}}=\sum_{j=1}^{m} w_{j}= \\
1 \\
s_{f k}=w_{\lambda f k} x_{i_{f} k} \\
S_{f}=\sum_{k=1}^{m_{f}} s_{f k}=\sum_{k=1}^{m_{f}} w_{\lambda f k} x_{i_{f} k} \\
s_{i j}=x_{i j W_{j}} \\
S_{i}=\sum_{j=1}^{m} s_{i j}=\sum_{j=1}^{m} x_{i j} w_{j} \\
S_{i_{f} k}=\sum_{k=1}^{m_{f}} x_{i_{f} k} w_{f k}
\end{gathered}
$$

Where $w_{\lambda k j}$ is the $k^{\text {th }}$ main factor corresponding to the $j^{\text {th }}$ variable; $s_{f k}$ is the $k^{\text {th }}$ main factor's cultural cognition score combined with weighting assigned by the eigenvalues and coefficient of variation; $x_{i_{f}}$ is the $f^{\text {th }}$ main factor's $k^{\text {th }}$ variable. $w_{f k}$ is the weight of the $f^{\text {th }}$ main factor's $k^{\text {th }}$ variable; $m_{f}$ is the number of the $f^{\text {th }}$ main factor, and $m_{f}<m . S_{f}$ is the main factors' cultural cognition score. Their mathematical relationship is $m_{f}<m, S_{f} \in\left[\begin{array}{ll}1 & 5\end{array}\right], s_{f k}<S_{f} \in\left[\begin{array}{ll}1 & 5\end{array}\right] . s_{i j}$ is the $i^{\text {th }}$ participant corresponding to the $j^{\text {th }}$ variable, $W_{j}$ denotes the $j^{\text {th }}$ variable's weight, $S_{i}$ denotes the $i^{\text {th }}$ participants' cultural cognitive score, and $S_{i} \in\left[\begin{array}{ll}1 & 5\end{array}\right] . S_{i_{f} k}$ is the $f^{\text {th }}$ main factor's cultural cognition score, $S_{i f k} \in\left[\begin{array}{ll}1 & 5\end{array}\right]$, and $x_{i_{f} k}$ is the $f^{\text {th }}$ main factor corresponding to the $k^{\text {th }}$ variable.

Tibetans' cognitive level is divided into three types: the high Tibetan traditional cultural cognitive type indicates Tibetans tend to inherit traditional culture; the medium cognitive type denotes a certain degree of Tibetan traditional and modern cultural cognition, which is the bicultural cognitive level; the low traditional cultural cognitive type means that Tibetans turn to modern culture.

The logical mathematical relation of high Tibetan traditional cultural cognitive types is as follows:

$$
S_{f}>3 \text { or } S_{i}>3
$$

The equation of the medium cognitive type is as follows:

$$
S_{f}=3 \text { or } S_{i}=3
$$

The formula for the low Tibetan traditional culture cognitive type is as follows:

$$
S_{f}<3 \text { or } S_{i}<3
$$

\subsubsection{The influencing factors analysis model}

The total score of cultural cognition, or the cultural cognition score, is associated with the above-mentioned aspects of daily life, tradition preservation, modern festivals, social interactions, and religious beliefs, which are the dependent variables. The influencing indicators corresponding to the items of alien cultural impacts, traditional cultural restrictions, policies, modern development, and social conditional change are the independent variables. The formula of the multiple stepwise linear regression analysis is as follows:

$$
S_{i}=S_{f}=\sum_{i=1}^{n} b_{i} x_{i}+\varepsilon_{i}
$$

Where $b_{i}$ is multiple linear regression coefficient, and $\varepsilon_{i}$ is the error term.

\section{RESULTS}

\subsection{Validity and reliability test}

The Kaiser-Meyer-Olkin measures of sampling adequacy (KMO) of all variables and influencing factors are 0.710 and 0.524 , respectively. The Standardized Cronbach's Alpha of all variables is 0.836 , and the corresponding values in terms of daily life, tradition preservation, modern festivals, social interactions and religious beliefs are $0.779,0.796,0.699,0.669$ and 0.676 , respectively. The Standardized Cronbach's Alpha of all influencing factors is 0.595 . Therefore, the variables and influencing factors are demonstrated to be valid, and the questionnaires have good authenticity and quality. 


\subsection{Tibetans' overall cultural cognition}

We use factor analysis and the coefficient of variation method to analyze the relative contribution to the overall cultural cognitive score (Table 1). The dimension of daily life makes the greatest contribution to the Tibetans' cultural cognition and change, and the ratio of the cognitive contribution is $33.490 \%$. The ratio of cognitive contribution in terms of traditional reservations $(27.432 \%)$ is greater than the corresponding contribution in the other three aspects, namely the modern festivals (14.656\%), social interactions $(13.861 \%)$ and religious beliefs $(10.560 \%)$. The specific cultural cognition characteristics of Tibetan people are as follows. The FMF has the greatest weight (0.091); FCW has weight 0.090, and NSH has weight 0.084 . Religious beliefs reflected by FHT and the FTB have weights 0.077 and 0.071 . Weights associated with the LTF and the LTC in daily life are the smallest and have values of 0.022 and 0.029. Daily life related total weights and scores are 0.265 and 0.878 ; the FCW has the largest weight (0.090). TNF has the largest cultural cognitive score (0.185), the weight and score for the LTF are the smallest (respectively 0.022 and 0.101 ). The total weight and score of traditional reservations are 0.240 and 0.967 . In terms of weight, the TTC and TME are greatest, with both at 0.067 . In terms of scores, the TME is greatest (0.269). CTF has the smallest weight (0.046). Modern festivals have a total weight and score of 0.175 and 0.389 ; FMF has the highest weight and scores of about 0.091 and 0.234 ; NSH has the smallest weights and scores of 0.084 and 0.155 . The social interactions weighting in the INT is 0.066 , and the highest score is for IMN (0.144). The NTR has the smallest cognitive weight and score, of 0.045 and 0.113 . The FHT in religious beliefs has the highest cultural cognitive weight and score ( 0.077 and 0.206 , respectively), but the cultural cognitive weight and score corresponding to the FTB are 0.071 and 0.202 .

Table 1. Tibetan people's cultural cognition in five dimensions

\begin{tabular}{|l|c|c|c|c|}
\hline Principal factors & Eigenvalues & C-weights & V-weights & The ratio of cognitive contribution ( \% ) \\
\hline Daily life & 2.967 & 0.265 & 0.787 & 33.490 \\
\hline Tradition preservation & 2.685 & 0.240 & 0.644 & 27.432 \\
\hline Modern festivals & 1.962 & 0.175 & 0.344 & 14.656 \\
\hline Social interactions & 1.909 & 0.171 & 0.326 & 13.861 \\
\hline Religious beliefs & 1.666 & 0.149 & 0.248 & 10.560 \\
\hline Total & 11.189 & 1.000 & 2.349 & 100 \\
\hline
\end{tabular}

Note: "C-weights" calculated by combing with factor analysis and the coefficient of variation method; "V-weights" computed by the methods about the coefficient of variation.

\subsection{Characteristics of Tibetan people's culture cognitive shifts}

Cultural cognitive weights and scores represent Tibetans' cultural cognition and shifts in terms of five dimensions (Table 2). The proportion of the overall cultural cognitive score higher than the mean cultural cognitive score value is $52.542 \%$, while the score higher than 3 accounts for $45.763 \%$, meaning that the ratio of scores between 2.959 and 3 is $6.779 \%$, but the proportion of the cultural cognitive scores below 3 is $54.237 \%$. The scores less than 3 in the modern festivals account for $74.576 \%$. Furthermore, the ratio of the Tibetans' cultural cognitive scores greater than 3 in traditional reservations is $79.661 \%$. In social interactions, the scores less than 3 account for $71.186 \%$. In the religious beliefs, the mean value of cognitive scores is 2.742 , the related distribution is $52.542 \%$, and the proportion of the cognitive scores equal to 3 is $25.424 \%$; the ratio of the cultural cognitive scores between 2.742 and 3 is $27.118 \%$, and the proportion of the cognitive scores superior than 3 is $27.119 \%$. The proportion of the cognitive scores less than 3 is $47.458 \%$ in the dimensions of religious beliefs. The Tibetans' average cognitive scores in daily life and traditional reservations are 3.310 and 4.030 , and the corresponding proportions of scores greater than 3 are $62.712 \%$ and $79.661 \%$.

Table 2. Statistical characteristics of Tibetans' cultural cognition at three levels

\begin{tabular}{|l|c|c|c|c|c|c|}
\hline \multirow{2}{*}{ Dimensions } & $<3$ & 3 & $>3$ & $<$ mean & $>$ mean & Mean \\
\cline { 2 - 7 } & Proportion(\%) & Proportion(\%) & Proportion(\%) & Proportion(\%) & Proportion(\%) & \\
\hline Total & 54.237 & 0 & 45.763 & 47.458 & 52.542 & 2.959 \\
\hline Daily life & 37.288 & 0 & 62.712 & 52.542 & 47.458 & 3.310 \\
\hline Tradition preservation & 16.949 & 3.390 & 79.661 & 45.763 & 54.237 & 4.030 \\
\hline Modern festivals & 74.576 & 6.780 & 18.644 & 55.932 & 44.068 & 2.217 \\
\hline
\end{tabular}




\begin{tabular}{|l|c|c|c|c|c|c|}
\hline Social interactions & 71.186 & 1.695 & 27.119 & 52.542 & 47.458 & 2.336 \\
\hline Religious beliefs & 47.458 & 25.424 & 27.119 & 47.458 & 52.542 & 2.742 \\
\hline
\end{tabular}

Tibetans adapt to traditional culture, and they also adjust to modern culture in daily life (Table 3). The proportion of above-average cultural cognitive scores (MPA) for LTF, LTC, TNF, PMW and FTL are $66.102 \%$, $61.017 \%, 61.017 \%, 52.542 \%$ and $59.322 \%$, respectively. This indicates that Tibetans tend towards Tibetan traditional culture in terms of diets, clothes, languages, friends and daily mountain worships. However, the value of MPA for FCW is $40.678 \%$. This indicates that the Tibetans also slowly adapt to modern culture in their occupational and economic activities. Tibetan people's average cultural cognition score (AS) for tradition preservation is 4.030 , the value of MPA is $47.458 \%$, and the proportion of cognitive scores more than 3 accounts for $79.661 \%$. This means the Tibetans primarily follow the traditional culture and also have high traditional cultural awareness. This is mainly reflected by TTC, TME and TTF; the related values of MPA are $54.237 \%$, $50.847 \%$ and $50.847 \%$ respectively. However, the value of MPA for CTF is $47.458 \%$, which implies that some traditional Tibetan customs are affected by modern culture to a certain extent. The value of MPA in modern festivals is $54.237 \%$, which represents FMF and NSH, and the corresponding MPA values are $50.847 \%$ and
$57.627 \%$, respectively. This indicates that Tibetans' cultural cognitive scores are mainly between 2 and 3 . Moreover, the ratio of scores less than 3 is $74.576 \%$, and the corresponding average score is 2.217 , which means that Tibetans adapt to the local modern cultures in terms of modern festivals. At the same time, the IMN is slightly higher than the value of MPA $(50.847 \%)$. Tibetans are deeply influenced by modern culture in social interaction: the proportion of scores greater than the mean is only $44.068 \%$, and the cultural cognitive mean value is 2.336 . Meanwhile, the MPA of the NTR and INT are $40.678 \%$ and $42.373 \%$, respectively. This means that the Tibetan people develop in-depth interactions with non-Tibetans. On the other hand, religious beliefs are rooted in Tibetan people's lives, but the religious cognition of the Tibetan people is influenced by the modern culture to a certain extent. The proportion of people with cultural cognition scores less than 3 is $47.458 \%$, and the average cognitive score is 2.742 , which means that the religious beliefs' cognition among Tibetan people has generally declined. However, the values of MPA for FTB and FHT are $66.102 \%$ and $61.017 \%$, reflecting that the effect of religious beliefs on the Tibetans is profound.

Table 3. The characteristics of cultural cognition and shifts of Tibetan people

\begin{tabular}{|c|c|c|c|c|c|c|c|}
\hline \multirow{2}{*}{ Dimensions } & \multirow{2}{*}{ Variables } & \multicolumn{3}{|c|}{ Main factors } & \multicolumn{3}{|c|}{ All variables } \\
\hline & & AW & AS & MPA(\%) & AW & AS & MPA(\%) \\
\hline \multirow{7}{*}{ Daily life } & LTF & 0.084 & 0.380 & 66.102 & 0.027 & 0.123 & 66.102 \\
\hline & LTC & 0.108 & 0.469 & 61.017 & 0.035 & 0.151 & 61.017 \\
\hline & TNF & 0.189 & 0.697 & 61.017 & 0.061 & 0.225 & 61.017 \\
\hline & DWS & 0.163 & 0.601 & 52.542 & 0.053 & 0.194 & 52.542 \\
\hline & FCW & 0.340 & 0.669 & 40.678 & 0.110 & 0.216 & 40.678 \\
\hline & FTL & 0.114 & 0.496 & 59.322 & 0.037 & 0.160 & 59.322 \\
\hline & Sub-sum & 1.000 & 3.310 & 52.542 & 0.323 & 1.070 & \\
\hline \multirow{5}{*}{ Tradition preservation } & TTC & 0.277 & 1.048 & 54.237 & 0.045 & 0.169 & 54.237 \\
\hline & TME & 0.278 & 1.123 & 50.847 & 0.045 & 0.181 & 50.847 \\
\hline & TTF & 0.254 & 1.048 & 50.847 & 0.041 & 0.169 & 50.847 \\
\hline & CTF & 0.190 & 0.811 & 47.458 & 0.031 & 0.131 & 47.458 \\
\hline & Sub-sum & 1.000 & 4.030 & 47.458 & 0.162 & 0.651 & \\
\hline \multirow{3}{*}{ Modern festivals } & FMF & 0.518 & 1.335 & 50.847 & 0.078 & 0.200 & 50.847 \\
\hline & NSH & 0.482 & 0.882 & 57.627 & 0.072 & 0.132 & 57.627 \\
\hline & Sub-sum & 1.000 & 2.217 & 54.237 & 0.150 & 0.332 & \\
\hline \multirow{4}{*}{ Social interactions } & NTR & 0.266 & 0.662 & 40.678 & 0.063 & 0.157 & 40.678 \\
\hline & INT & 0.388 & 0.829 & 42.373 & 0.092 & 0.196 & 42.373 \\
\hline & IMN & 0.346 & 0.845 & 50.847 & 0.082 & 0.200 & 50.847 \\
\hline & Sub-sum & 1.000 & 2.336 & 44.068 & 0.237 & 0.553 & \\
\hline
\end{tabular}




\begin{tabular}{|l|l|l|l|l|l|l|l|}
\hline \multirow{4}{*}{ Religious beliefs } & FTB & 0.479 & 1.357 & 66.102 & 0.062 & 0.175 & 66.102 \\
\cline { 2 - 8 } & FHT & 0.521 & 1.385 & 61.017 & 0.067 & 0.178 & 61.017 \\
\cline { 2 - 8 } & Sub-sum & 1.000 & 2.742 & 47.458 & 0.129 & 0.353 & \\
\hline \multirow{2}{*}{ Total } & & & & 52.542 & 1.000 & 2.959 & 52.542 \\
\hline
\end{tabular}

Note: "AW" means the average weight; "AS" refers the average cultural cognitive score; "MPA" indicates the proportion of more than the average cultural cognitive score.

\subsection{Influencing factors analysis of Tibetans' cultural cognition and shifts}

The factors affecting the cultural cognition and shifts are the indexes about the influence of IA, IC, NP and MR. The variable IA has a positive effect, meaning that the influence of alien culture makes Tibetans' cognition tend towards traditional Tibetan culture, while the variables IC, NP and MR have negative effects, so the interest in alien culture, national policies and mixed residence reduce the traditional cultural cognitive level. The influencing factors are EL, IA, IC, NP and IE in terms of daily life. The results show that a lower level of education is correlated to a higher tendency towards traditional culture; also, a greater influence of alien culture impacts on the protection of Tibetan traditional culture. On the other hand, interest in alien cultures, influences from national policies, and educational facilities' improvement reduce Tibetans' traditional cultural cognition and boost their acceptance of modern culture. From the aspect of tradition preservation, the influencing factors are age, EB, NP, GL and PD. This shows that older Tibetans tend to have a stronger sense of ethnic belonging, leading to a preference for their traditional culture. A higher level of globalization also encourages people to protect traditional symbols that comply with traditional rules. However, the impact of national policies and the internal response level of people's all-round development could promote people to adapt to modern culture. Moreover, a stronger national policy means a higher level of perception of modern culture among Tibetans. In addition, better internal comprehensive development is usually accompanied by a decline in traditional cognition and a preference for modern culture.

In terms of cultural cognition of modern festivals, the influencing elements include FA and TA. This indicates that greater familiarity with alien cultures is associated with a higher cultural awareness of modern festivals. Meanwhile, using modern technology could cause a decrease in traditional culture cognition. In the social interactions aspect, the influencing components are MR and IC. This means that a higher degree of ethnically mixed residence enhances cultural exchanges between Tibetans and non-Tibetan people, resulting in a higher cognition of modern culture. The interest in alien cultures can also enhance modern cultural cognition. In terms of religious beliefs, the affecting factors are IA, EB, MR and PD. This aspect shows that a greater influence of alien cultures enhances the sense of ethnic belonging associated with the traditional cultural cognition; this indicates stronger religious beliefs and protection of spiritual sustenance. However, a higher level of racially mixed living and higher need for an internal overall development response lowers Tibetans' religious faith and raises their preferences for modern culture.

\section{DISCUSSION}

\subsection{General discussions of Tibetans' cultural cognition and shifts}

The transformation of Tibetan local cultural could lead to the disappearance of native culture and the cultural heterogeneity [10]. Thus, it is of great importance to consider the relationship among Tibetan local cultural characteristics, pluralism and sustainability. This will provide constructive suggestions for the local government ministries, as well as for social and cultural management departments in terms of social harmony construction, economic development, technological investment and project implementation. Understanding of local culture and also avoid the misunderstanding of how modern mainstream cultural dominance is perceived in the ethnic minority-dominated region. Tibetan local culture is divided into traditional and modern cultures, which provides some references for ethnic cultural analysis. Meanwhile, using the coefficient of variation weighting method to calculate Tibetans' cultural cognitive scores, and combining these with factor analysis and the coefficient of variation weighting method, strongly demonstrates the robustness of the method.

The Tibetan Plateau has forged a unique Tibetan local culture, due to its rich historical and cultural environment, for example, the Buddhist culture and Tibetan traditional culture. The cognitive approach and way of thinking are unique, and often lie on the boundary between reality and spirituality. Since 1978, when Tibet entered the era of the reform and opening up, modern cultures have progressively and profoundly affected their cognition associated with psychological activities, lifestyles and social behaviors. These changes have influenced Tibetan traditional and modern cultural components. This reflects underlying historical, political, economic, religious, social and political drivers. As a result, an increasing number of Tibetans are integrated into multicultural environments. This shift arises not only due to population migration, but also due to globalization, higher traveling speed and the introduction of new technology [23]. In 
Tibet, modern and traditional cultures are ubiquitous: in classrooms, companies, restaurants, entertainment venues, shopping malls, supermarkets, and even in TV programs and on the internet. Traditional and modern cultures represent many matching ways of independence, adaptation, integration and mutual enculturation.

Both daily life and tradition preservation have the greatest contribution to Tibetans' cultural cognition, and religious beliefs contribute the least to the overall score. Modern festivals and social interactions are intermediate. This reflects two main reasons: on the one hand, Tibetans have cultural cognitive path dependence [24]. Some complex attitudes held by residents can only be expressed indirectly through behaviors, customs and traditions; on the other hand, residents have Tibetan cultural awareness. In the context of contemporary society, Tibetans are undergoing cultural cognition that faces two key issues: firstly, which choice motivates them, and secondly, whether they are allowed to maintain their ethnic culture or be involved in the modern culture. From the dialectical analysis of Tibetan people's social participation and psychological responses, we find that cultural cognitive shifts represent the psychological displacement of crossspace mappings among different cultures. The greater the psychological capacity, the higher the Tibetans' different cultural perceptions of their own culture. This is because social and psychological factors can promote Tibetans' cultural empathy. In general, approximately $50 \%$ of people's cultural cognition gradually turns to modern cultures, largely representing modern festivals and social interactions. In the process of cultural cognition, Tibetan people establish a dialectical process of contradiction between new self-concept construction and selfconceptual disturbance. This will then integrate tradition into modern elements. Tibetans' cultural cognition and changes are influenced by the modern development and the level of internal responses about people's own comprehensive development, enabling breakthrough and creation of cognitive paths, and raising people's modern cultural awareness.

Tibetans' perceptions of traditional values have changed to some extent. The ingredients causing cognition shifts have certain differences in daily life, traditional reservations, modern festivals, social interaction and religious beliefs. The variables of gender, age, ethnicity, the level of education and occupation represent Tibetans' socioeconomic status. However, the main influences are the level of education and age. On the one hand, Tibetans with higher levels of education more readily face and understand modern culture. On the other hand, the inertial force of cognitive proximity promotes Tibetans' older people to become more cognizant of traditional culture. Their ability to perceive external stimuli weakens with age. Consequently, age has an important influence on Tibetans' cultural cognition. Additionally, results show that ethnic cognition, cultural stress and self-concept vary from gender to gender [25].
There are commonalities that cause Tibetans' cultural cognition. Less than $50 \%$ of the people have cultural cognition in daily life, traditional reservations and religious beliefs that inclines to modern culture. In particular, nearly $80 \%$ of Tibetans in traditional reservations abide by traditional cultural practices. This reflects the need for cognitive closure in response to cultural cognition; this is implicit in social events. Besides, cultural cognition is an image schema depending on the knowledge structure of people. Therefore, the level of education and the degree of educational facilities' improvement affect cultural cognitive scores in daily life. However, the image schema also varies to some extent with the acquisition of human experience. With Tibet's ongoing social, modern advancement, Tibetans generally enjoy the benefits brought about by modern development, so the level of education and the degree of educational facilities' improvement have little effect on the cultural cognition and shifts. Cultural cognition exhibits two complementary natural and not-natural characteristics. Both traditional reservations and religious beliefs are influenced by the level of internal responses about people's own comprehensive development. This is largely reflects how Tibetans are in the process of unconscious or primitive practices between their self and other cultures, and emphasizes self-objective existence [26]. However, the Tibetans' cultural cognition and shifts in daily life, modern festivals and social interactions are not affected by the natural factors of the level of internal responses about people's own comprehensive development. This is usually due to non-natural factors associated with cultural cognitive norms, practices and institutional arrangements. The level of internal responses regarding people's own comprehensive development belongs to the natural process of human desire and actual needs, and essentially does not influence Tibetans' perceptions in daily life, modern festivals and social interactions.

In summary, Tibetans who have greater psychological stress to alien culture will have higher traditional awareness and experience stronger protection awareness from their self-cognitive system. In other words, this would generally be explained by the connection between social and psychological aspects. Pressures from alien culture could promote the disturbance and reconstruction of the self-concept system, and evoke Tibetans' defense awareness of modern factors [27]. People's modern cultural acceptant ability is enhanced by the level of Tibetan and non-Tibetan mixed residence and the degree of interest in alien cultures. National investment, aid and related policies in Tibetan have wholly improved Tibetans' modern cultural recognition and adaptation. This is consistent with the conclusions of economic and political factors that influence cultural cognition and adjustment. 


\subsection{Tibetans' cultural cognition and shifts in five dimensions}

In terms of daily life, Tibetans with a lower level of education tend to recognize their traditional culture more. Similarly, Tibetans' psychological stresses from modern culture could also stimulate traditional cultural recognition. Yet, interest in modern culture has a positive effect on the recognition of local modern culture. Our results indicate that Tibetans judge their typicality and atypicality to their ethnic group by focusing on demographic features, values and behaviors. Additionally, a previous study has found that their own ethnic cultural cognition, or the level of perceived typicality, is inversely related to the measures of ethnic cognition and well-being. For this reason, a higher level of national policies' impact and a higher degree of educational facilities' improvement could accelerate Tibetans' sense of accomplishment and happiness in their production and living standards. This would further boost their cultural cognition turning to modern culture in daily life. However, in daily life, the degree of ethnic belonging and the degree of Tibetan cultural restriction on behavior have no effect on Tibetan cultural cognition. This demonstrates, to some extent, that there is no significant direct correlation between cognition and traditional restrictions.

In traditional reservations, age is an important norm. The Tibetans who are older would receive more traditional culture. Due to the cultural inertia in terms of the old people's knowledge structure and language skills, the locking effect could further strengthen the embeddedness of the Tibetan aged people's traditional cultural perception [24]. From the perspective of modern festivals, the level of familiarity of alien culture and the level of technical application can increase Tibetans' modern cultural cognition. Those Tibetans who are more familiar with modern culture are more knowledgeable of modern festivals. This could also improve integration into the modern culture. Meanwhile, technological progress is an endogenous force for cultural development and cultural cognitive shifts [28]. With regard to social interactions, the level of Tibetan and non-Tibetan mixed residence could prompt Tibetans to easily turn to modern cultural cognition. Cultural comfort theory believes that personality, cultural adaptability and psychological wellbeing could affect people's attitudes [23]. This is because mixed living surroundings may promote communication and integration among people in terms of diets, clothes, living habits, festivals and beliefs. This could give impetus to Tibetans' cultural cognition shifts. With regard to religious beliefs, the influence of alien culture and the degree of ethnic belonging could promote Tibetans' traditional cultural perception. Religious cultural embeddedness could cause Tibetans to drift away in the traditional and modern culture. However, the level of Tibetan and non-Tibetan mixed residence and the level of internal responses to their own comprehensive development could lessen traditional cognition and could encourage Tibetans to abandon religious faiths. Meanwhile, modern development could effectively evade Tibetans' religious ideology. The positive factors of modernization are reflected in their spiritual pursuit and the practical actions of the local people's modern culture. So, the Tibetans could positively adapt to modern culture.

Finally, there are some limitations of this research. The cultural cognitive score is divided into more than 3 , equal to 3 and less than 3 , but the contributing factors underlying the above three mentioned types were not analyzed. Tibetan local cultural cognitive characteristics do not explore the different age of Tibetans. The study did not consider the time lag of policies affecting Tibetans' cultural cognition. Gender, OP, RT, AO, BR, ED, UI, AC, LG, OC and SS do not directly cause Tibetans' cultural cognitive changes; however, assessing whether these indicators have mediating effects still requires further exploration.

\section{CONCLUSIONS}

Since the peaceful liberation in Tibet, especially since the reform and opening up, Tibetans have been influenced by modern cultures. This has led to Tibetan people's self and other cultural cognition. Daily life, tradition preservation, modern festivals, social interactions and religious beliefs together constitute the contemporary Tibetan local culture. The above five aspects also construct Tibetans' contemporary local cultural perception and drive its shifts. The contributions of the five Tibetan local cultural components listed from greatest to smallest are daily life, tradition preservation, modern festivals, social interactions and religious beliefs. This shows that daily life and tradition preservation are the main contributing factors constituting Tibetan people's cultural cognition. The integration of Tibetans' cultural cognition can be represented in the aspects of daily life, tradition preservation and social interactions. However, Tibetans' traditional cultural cognition in religious beliefs reflect cultural separation. In addition, Tibetans tend towards modern cultural cognition in their economic.

Tibetans' cultural cognition is strongly influenced by the Tibetans' psychological response and Tibetan social development. Tibetan people's traditional and modern cultural cognition fully reflects the dialectical unity of nature and not-nature, typical and atypical, endogenous and exogenous forces, positive and negative effects, path dependence and path creation, self-concept disturbance and self-concept reconstruction, as well as material pursuit and spiritual enjoyment. Besides, the influencing factors of alien cultural pressure, the level of education, age, the degree of ethnic belonging, and the level of globalization could affect Tibetans' adherence to traditional culture. Meanwhile, changes in social relations, positive effects of alien culture, the 
improvement of educational facilities, the level of modern science and technology usage and the implementation of the national policies could all improve modern cultural cognition of Tibetans.

\section{AUTHORS' CONTRIBUTIONS}

Yan Sun researched, processed data, analyzed data, designed article frames, and wrote the article. Hao Zhang revised the full text of the article. Weiwei Wang proposed suggestions on writing and editing the article.

\section{ACKNOWLEDGMENTS}

Professor Yongchun Yang who is from the College of Earth and Environmental Science of Lanzhou University gave the manuscript many endorsement, thanks to his guidance, suggestions and revisions. Thanks to the funding of the Ph.D. Research Startup Fund Project (1192932001) of Jiangsu University of Science and Technology.

\section{REFERENCES}

[1] B.M.Ferdman, Literacy and cultural identity. Harvard Educational Review 60(2) (1990) 181-204. DOI:https://doi.org/10.17763

/haer.60.2.k10410245xxw0030

[2] S.W.Carvalho, L.G.Block, S.Sivaramakrishnan, et al., Risk perception and risk avoidance: The role of cultural identity and personal relevance. International Journal of Research in Marketing, 25(4) (2008) 319-326. DOI: https://doi.org/10.1016/ j.ijresmar.2008.06.005

[3] M.L.Miville, D.Koonce, P.Darlington, et al., Exploring the relationships between racial/cultural identity and ego identity among African Americans and Mexican Americans. Journal of Multicultural Counseling \& Development 28(4) (2000) 208-224. DOI: $\quad$ https://doi.org/10.1002/j.21611912.2000.tb00616.x

[4] R.S.Bhagat, S.J.McQuaid, Role of subjective culture in organizations: A review and directions for future research. Journal of Applied Psychology 67(5) (1982) 653-685. DOI: https://doi.org/10.1037/0021-9010.67.5.653

[5] D.Bhugra, Migration, distress and cultural identity. British Medical Bulletin 69(1) (2004) 129-141. DOI: https://doi.org/10.1093/bmb/ldh007

[6] N.Yagi, J.Kleinberg, Boundary work: An interpretive ethnographic perspective on negotiating and leveraging cross-cultural identity. Journal of International Business Studies 42(5) (2011) 629-653. DOI: https://doi.org/10.1057/jibs.2011.10
[7] L.Robinson, Cultural identity and acculturation preferences among South Asian adolescents in Britain: An exploratory study. Children \& Society 23(6) (2009) 442-454. DOI: https://doi.org/10.1111/j.1099-0860.2008.00179.x

[8] Q.Zhang, P.Xu, A investigation into the current situation of cultural identity of Tibetan farmers and herdsmen: based on the survey of two villages in Tibetan agricultural and pastoral areas. Journal of Southwest University for Nationalities (Humanities and Social Science) 33(9) (2012)16-20.

[9] K.Guan, Modernization and cultural transformation of ethnic minorities. Journal of South-Central University for Nationalities (Humanities and Social Sciences) 6 (2002) 45-48.

[10] A.Z.Yuan, F.Guo, Y.Z.Li, An analysis of the value concern and basic appeal of the spread of Tibetan culture in the new era. Journal of Xizang Minzu University (Philosophy and Social Sciences Edition) 39(4) (2018)19-26+154.

[11] M.L.Eyou, V. Adair, R.Dixon, Cultural identity and psychological adjustment of adolescent Chinese immigrants in New Zealand. Journal of Adolescence 23(5) (2000) 531-543. DOI: https://doi.org/10.1006/jado.2000.0341

[12] H.W.Xu, "Fei Xiaotong's difficult problem": realistic tension and theoretical response to the modernization and cultural transition of ethnic minorities. Journal of Hubei University for Nationalities (Philosophy and Social Sciences) 36(6) (2018) 116-121.

[13] N.M.Sussman, The dynamic nature of cultural identity throughout cultural transitions: Why home is not so sweet. Personality \& Social Psychology Review 4 (2000) 355-373.DOI: https://doi.org/10.1207/S15327957PSPR0404_5

[14] A.M.Moore, G.G.Barker, Confused or multicultural: Third culture individuals' cultural identity. International Journal of Intercultural Relations, 36(4) (2012) 553-562.

[15] Y.L.Yan, New planned economy or "new bird cage economy". Economic Herald 8 (2017) 65-69.

[16] W. Wei, B.X.Li, Y.L.Jiao, Study on the evolution and pattern of central cities in Tibetan Area. Architectural Journal 7 (2007) 80-84.

[17] N.E.Levine, Buddhism in Contemporary Tibet: Religious Revival and Cultural Identity, in: C. GoldsteinMelvyn, T. KapsteinMatthew (Eds.), University of California Press, 1998.

[18] M.Félix-Ortiz, M.D.Newcomb, H.Myers, A 
multidimensional measure of cultural identity for Latino and Latina adolescents. Hispanic Journal of Behavioral Sciences 16(2) (1994) 99-115.

[19] W.H.Wang, Research on the habitat, characteristics and identity of Tibetan Netizen's using internet culture. Journal of Ethnology, 8(4) (2017) 3538+105-107.

[20] W.W.Lang, S.B. Zhao, Tibet population characteristics and structure optimizations study. Tibetan Studies 6 (2016) 75-81. DOI: https://doi.org/1000-0003 (2016 )06-0075-07

[21] L.Yong, M.G.Wan, On the factors that influence the Han and Tibetan culture identity status of the Tibetan undergraduates. Studies of Psychology and Behavior, 3 (2003)181-185.

[22] T.Yuan, Eco-city construction: an analysis of the development and transformation of Zhangye. Lanzhou: Lanzhou University (2018).

[23] Q.L.Huynh, V.Benet-Martínez, A.M.D.Nguyen, Measuring variations in bicultural identity across U.S. ethnic and generational groups: Development and validation of the bicultural identity integration Scale-Version 2 (BIIS-2). Psychological Assessment (2018)1-16.

DOI: https://doi.org/10.1037/pas0000606

[24] H.W.Li, X.H.Qu, Path evolution: Seeking path creation by going beyond path dependence. Journal of Sichuan University (Social Science Edition) 2 (2012) 108-114. DOI: https://doi.org/1006-0766 (2012) 02-0108-07

[25] J.Zhenduan, F.Jacquez, E.SáezSantiago, Boricua de puracepa: Ethnic identity, cultural stress and selfconcept in Puerto Rican youth. Culture Divers Ethnic Minor Psychol24(4) (2018) 588-595. DOI: https://doi.org/10.1037/cdp0000199

[26] D.Hoyos, P.Mariel, J.Fernández-macho, The influence of cultural identity on the WTP to protect natural resources: Some empirical evidence. Ecological Economics 68(8) (2009) 2372-2381. DOI:

https://

doi.org/10.1016/j.ecolecon.2009.03.015

[27] Umney M, Rassekh F. (2018). Using relationship to explore the development of cultural identity and the dynamics of oppression and repression. Transactional Analysis Journal,48(2):192-205. https://doi.org/ 10.1080/ 03621537. 2018. 1429314

[28] Y.O. Zhang, R.X.Gu, The geography of knowledge complexity and its influence in Chinese cities. Acta Geographica Sinica 73(8) (2018) 1421-1432. DOI: https://doi.org/10.11821/dlxb201808003 